\title{
Die Afrikaanse letterkunde in 'n amptelik Engels-eentalige Suid-Afrika
}

\begin{abstract}
In this article the situation of Afrikaans literature in an officially English monolingual South Africa is discussed. The growth and decline of languages are influenced by so many factors and processes that it is impossible to predict precisely how loss of official status and the concomitant loss of important legal and conventional language rights presently enjoyed by Afrikaans speakers would affect Afrikaans. Nevertheless it is certain that at least three areas will be affected. Firstly, loss of recognition and the anglicization of tertiary education will bring about a decline in Afrikaans as a scientific language, resulting in a loss in diversity and the decay of cenain registers. The anglicization of the electronic mass media will deprive Afrikaans of a crucial function of a modem language - serving its community as the medium of information and recreation. The role of radio and $T V$ in providing an example of standard language use will disappear. Secondly, with English the sole official language, it is very probable that a language shift from Afrikaans will take place, a major calastrophe for any language. A dwindling body of readers affects any literature or publishing industy directly. Thirdly: loss of status will have economic repercussions, making it increasingly difficult for the Afrikaans community to buy and for publishers to produce books.
\end{abstract}

\section{Inleidend}

Laat ons begin met ' $n$ vraag aan die leser van hierdie stuk: Lyk dit vir u moontlik dat daar opskrifte soos die volgende in Suid-Afrikaanse koerante kan verskyn? "As Engelssprekendes nie oppas nie, kan hul taal verdwyn". "Engels is aan die verdwyn, sê professor." "Engelse taal loop gevaar om houvas in S.A. te verloor/Oud-hoofregter waarsku."

Opskrifte soos die is vandag ondenkbaar, en tog was hulle 30,35 jaar gelede meermale te sien. Die drie aangehaalde opskrifte het onderskeidelik op 31 Januarie 1956, 29 Oktober 1957 en 6 Februarie 1958 in Die Volksblad verskyn. Die professor wat in 1957 gewaarsku het, was die hoogs gerespekteerde historikus L.M. Thompson, en die oud-hoofregter was A. van de Sandt Centlivres.

Vandag kan 'n mens glimlag oor die Engelssprekendes se vrese, maar in die jare vyftig en sestig was dit vir hulle reëel. Voor republiekwording in 1961 was die Engelssprekendes bekommerd oor die moontlikheid dat Engels as ampstaal afgeskaf kan word. Sou dit dalk kan wees - om in die politieke idioom van ons tyd te bly - dat dit nie net Afrikaners is wat 'taal- en identiteitsbehep' is nie? Hoewel dit glad nie die Afrikaners se plan was om Engels 
sy amptelike status te ontneem nie, het Engelssprekendes hulle sterk teen so 'n moontlikheid verset en daarby in die jare sestig begin met aksies om hul taal verder te versterk.

Die belangrikste woorde in die Suid-Afrikaanse debat oor taal in 'n nuwe bedeling is amptelike status en verwante woorde soos ampstaal. Wat is 'n ampstaal en waarom het dit in die Suid-Afrikaanse debat so belangrik geword? Op hierdie vraag word ingegaan in afdeling 1 van hierdie artikel. Nog 'n algemene saak, naamlik die begrip letterkande kom in afdeling 2 aan die orde, terwyl verskillende soorte moontlike gevolge van die verlies van ampstaalstatus in afdelings 3, 4 en 5 aan die beurt kom.

\section{Ampstaalstatus}

Die terme taalstatus en ampstaal word op verskillende maniere in die literatuur gebruik. 'n Deskundige oor taalbeplanning, Juan Cobarrubias, skryf dat die begrip taalstatus glibberig en ingewikkeld is. Dit is konteks-bepaald en verander met verloop van tyd (Cobarrubias, 1983:43). Heinz Kloss wat bekend is om sy werke oor etnopolitiek, het 'n nuttige onderskeid getref tussen verskillende soorte taalstatus. 'n Mens kan die term taalstatus toepas op die juridiese status van 'n taal, sy stadium van ontwikkeling, sy aantal sprekers of sy gebruiksfunksies. (Cobarrubias (1983:43) gee daarvan 'n nuttige samevatting). In hierdie artikel word die term status voorbehou vir juridiese status, maar die verband daarvan met die ander soorte status sal hopelik later duidelik word.

Wat juridiese status betref, kan 'n taal ampstaal of mede-ampstaal oor die hele land of ' $n$ bepaalde streek wees, of ' $n$ taal wat vir bepaalde gebruiksfunksies bevorder word, of ' $n$ toegelate of verbode taal (Cobarrubias, 1983:44-45).

Die betekenis van die term ampstaal is ook nie sonder meer duidelik nie. In sommige lande is dit die taal van die regering en die parlement (Van Rensburg, 1990). Vir die VVO-organisasie Unesco is ' $n$ ampstaal weer die taal wat vir wetgewende, uitvoerende en regterlike aangeleenthede van die staat gebesig word (Unesco, 1968:689). Die SuidAfrikaanse betekenis kom meer ooreen met die omskrywing van die taalsosioloog Joshua Fishman, naamlik dat die ampstaal ' $n$ taal is wat erken en gebruik word vir regeringsdoeleindes, formele onderwys, die howe ensovoorts (Fishman, 1971). Walters (1978:307) voeg 'n belangrike implikasie van erkenning by wanneer hy verklaar dat ' $n$ ampstaal die taal is waarin amptelike sake volgens wet waargeneem moet word, of waarin 'n burger die reg het om met die owerheid in aanraking te kom. Die taalbelang van die burger word dus hiermee uitdruklik erken. Schuring (1960:6) neem al hierdie elemente in sy omskrywing op. 'n Ampstaal is vir hom die taal wat vir sommige of alle owerheidsfunksies op sommige of alle regeringsvlakke gebruik word en wat 'n landsburger vir kommunikasie met die owerheid regtens kan gebruik. 'n Addisionele taal word bykomend tot die ampstaal vir sommige owerheidsfunksies op sommige of alle regeringsvlakke gebruik.

Nog twee standpunte is verhelderend. Die eerste is dié van Alcock, Taylor en Welton (1979:193-194) wat belangrike implikasies van ampstaalerkenning vermeld. Sodanige erkenning verleen status aan die taal, gee sielkundige sekerheid aan die gebruikers daarvan oor hul plek in die staat en maak dit vir die taal moontlik om steun van die sentrale regering te verkry. 
Cooper (1989:100) maak 'n nuttige onderskeid tussen statutêre, werk- en simboliese ampstale. Eersgenoemde is 'n taal wat 'n regering deur middel van wetgewing as ampstaal verklaar het; 'n werktaal is 'n taal wat 'n regering van dag tot dag vir sy werksaamhede gebruik, en 'n simboliese amptelike taal is 'n taal wat 'n regering as 'n medium vir simboliese doeleindes gebruik, byvoorbeeld as 'n simbool van die staat.

\subsection{Taalregte}

In Suid-Afrika was artikel 137 van die Zuid-Afrika-Wet van 1909 dekades lank die riglyn vir die reël van taalregte. Die artikel het twee bepalings bevat. Die eerste lui:

De engelse alsmede de hollandse talen zijn officiële talen van de Unie. Zij worden op een voet van gelijkheid behandeld en bezitten en genieten gelijke rechten en voorrechten.

Die tweede bepaling lui soos volg:

Alle akten, verslagen en verrichtingen van 't Parlement worden in beide talen gehouden en alle wetsontwerpen, wetten en kennisgevingen van algemeen publiek gewicht of belang door de Regering van de Unic uitgegeven, zijn en geschieden in beide talen. (Anon., 1910:253.)

Die tweede bepaling was redelik spesifiek, maar die interpretasie van die eerste bepaling was moeiliker. Daar was geensins eenstemmigheid oor wat die implikasies daarvan was nie. Het 'n landsburger die reg om te verwag dat 'n amptenaar hom in Hollands (Nederlands of Afrikaans) te woord staan indien hy daarin aangespreek word? Die Nasionale Party het op hierdie vraag bevestigend geantwoord, die Unioniste en die meerderheid lede van die Suid-Afrikaanse Party het dit ontken.

Maar hoe ook al, deur die jare is verskillende soorte wetgewing aangeneem en besluite oor werksaamhede van die staatsapparaat uitgevoer met 'n beroep op artikel 137. Die Transvaalse Provinsiale Raad het byvoorbeeld in 1916 ' $n$ taalordonnansie gekry wat munisipaliteite verplig het om die bepalings van artikel 137 toe te pas. Die Kaapse Provinsiale Raad het in 1923 'n soortgelyke ordonnansie verwerp. Toe die Nasionale Party in 1924 saam met die Arbeidersparty aan bewind kom, het ministers op grond van artikel 137 begin om kennis van albei die ampstale vir aanstelling en bevordering in die staatsinstellings te vereis. Met die instelling van 'n radiodiens is voorsiening gemaak vir sowel Afrikaans as Engels.

Die gelykheid wat Afrikaans en Engels in beginsel in die geregshowe en ander openbare instellings geniet, asook die feit dat albei oor die radio en televisie en as onderrigmediums op skool en universiteit gebruik kan word, is klaarblyklik deur die verskillende regerings beskou as regte wat voortkom uit die grondwet asook, mettertyd, die konvensie wat sedert 1910 ontstaan het.

In 1963 was daar 'n betekenisvolle wysiging van die taalbepalings van die grondwet deur voorsiening daarvoor te maak dat ook die Afrika-tale in bepaalde streke amptelike status kan verkry.

'n Mens kan terloops daarop wys dat dit lyk of Namibië in sekere opsigte die SuidAfrikaanse opvatting aanvaar het oor wat 'ampstaalstatus' impliseer. Die Namibiese grondwet bevat ' $n$ betreklik algemene en selfs akkommoderende formulering, ${ }^{1}$ maar 
sonder dat daar enigiets oor die staatsbeheerde massamedia in die taalartikel staan, is die bepaling dat Engels die enigste ampstaal is, gebruik as regverdiging daarvoor om Afrikaans af te skaf as televisietaal. Die Namibiese Uitsaaikorporasie het die eerste stap in die uitfaseringsproses, naamlik die afskaffing van Afrikaans vir televisienuus, geregverdig deur aan te voer dat die besluit geneem is "ooreenkomstig die landsbeleid dat Engels die enigste ampstaal is" (Anon, 1990a). ${ }^{2}$ Nog later het Engels prakties die enigste televisietaal geword omdat dit ook die ampstaal is.

In hierdie artikel word 'amptelike status' gebruik met sy tradisionele Suid-Afrikaanse betekenis en implikasies van 'gelyke vryheid, regte en voorregte' vir die ampstale. Min mense het nog in die huidige debat 'n ander opvatting uiteengesit; dit het hoofsaaklik gegaan oor die vraag wat die ampstale moet wees. Wat dit betref, is verskillende voorstelle al gedoen, onder meer Schuring (1990).

Hoewel dit in 1991 gelyk het asof belangrike partye taalgelykheid voorstaan, was daar heelwat Suid-Afrikaners, ook Afrikaanse letterkundiges, wat meen dat Engels die enigste ampstaal moet wees, onder meer omdat hulle die opvatting het dat die juridiese status van 'n taal wesenlik geen saak aan die lewenskrag van ' $n$ taal maak en dus geen direkte invloed sal hê op die Afrikaanse letterkunde nie.

\section{Literatuur/ letterkunde}

Dit is binne die bestek van hierdie artikel onmoontlik om die begrip letterkunde diepgaande te bespreek. 'n Definisie van letterkunde is egter altyd tyd- en ruimtelik bepaald. Enige definisie van hierdie begrip kan daarom ook nooit meer as 'n hipotetiese status hê nie. Sedert Aristoteles se Poetica is daar al 'n debat oor die verband tussen letterkunde en werklikheid. Aan die een kant is die letterkunde gesien as verbonde met die werklikheid (en die gemeenskap); aan die ander kant is letterkundige tekste later a! hoe meer gesien as 'n afgeslote korpus 'estetiese' tekste. In hierdie artikel word gefokus op die letterkunde, maar daar sou ook verwys kon word na die begrip literatuur wat 'n veel

${ }^{1}$ Die artikel lui soos volg:

"(1) Die amptelike taal van Namibië sal Engels wees.

"(2) Niks wat in hierdie grondwet vervat is, sal die gebruik van enige ander taal as medium van onderrig belet in beide private skole en skole wat deur die Staat gefmansicr of gesubsidieer word nie, onderhewig aan die nakoming van sodanige vereistes as wat by wet ingestel mag word om vaardigheid in die amptelike taal te verseker, of vir opvoedkundige redes.

"(3) Niks wat in sub-paragraaf (1) hierbo vervat is sal die Parlement belet om wetgewing te aanvaar nie wat die gebruik van tale anders dan Engels magtig vir wetgewende, administratiewe en regsprekende doeleindes in streke of gebiede waar sodanige ander taal of tale deur ' $n$ beduidende komponent van die bevolking van daardie streke of gebiede gebesig word."

2 Dis die formulering van die Namibia Broadcasting Corporation. Die direkteur-generaal van die Namibia Broadcasting Corporation, mnr. Nahum Gorelick, het later gesê dat die NBC briewe van protes ontvang het, maar dal die besluit nie verander word nie omdat Engels die landstaal is. 
omvattender term is. So 'n omvattender benadering is ook makliker versoenbaar met die uitgangspunte van die sogenaamde polisisteem. Binne hierdie teorie word taal en literatuur gesien as ondergeskik aan 'n veel groter kulturele sisteem. Dit gaan daarom hier ook oor die netwerk van verhoudings - nie net tussen 'tekste' nie, maar tussen al die komponente waaruit 'n literatuursisteem bestaan. Dit sluit nie net voor die hand liggende komponente in soos uitgewers, tydskrifte en skrywersgroeperinge nie, maar ook regeringsen opvoedkundige instellings en selfs religieuse belangegroepe. Die gevolg van so 'n benadering is dat ' $n$ mens besef dat enige sosiale of politieke verandering byvoorbeeld die betrokke literêre sisteem direk kan beînvloed. Enige verandering aan die status van ' $n$ ampstaal gaan daardie taal as kultuurtaal en daarom ook as literêre taal direk raak.

Dit is skaars nodig om te beklemtoon dat die voortbestaan, groei en agteruitgang van tale nie voorspel kan word nie. Van Wyk Louw (1986:90) haal 'n uitspraak van die teoloog Skinner aan wat hy die "dierbaarste uitdrukking" noem wat hy van 'n teoloog ken: "It is certain that Jeremiah was left in the end with a considerable margin of unfulfilled prediction on his hands." Die spoedige dood van Afrikaans is van die negentiende eeu af meermale gesaghebbend voorspel - ook in die tyd toe mense soos ds. S.J. du Toit met hul taalbeweging begin het. Hulle het voortgegaan asof die voorspellings nie gemaak is nie, 'n koerant gestig, boeke uitgegee ... en hulle vir die amptelike status van Afrikaans en Nederlands beywer.

Tog moet 'n mens rekening hou met moontlike, selfs waarskynlike, gevolge van die verlies van ampstaalstatus: kulturele, demografiese en ekonomiese gevolge.

\section{Kulturele gevolge van die verlies van ampstaalstatus}

Ten eerste die moontlike gevolge van taal- en kulturele aard wat dus betrekking het op Afrikaans as kultuurtaal. Die ervaring leer dat, wanneer 'n kragtige taal soos Engels amptelike erkenning geniet en die ander tale nie, die amptelike taal as 't ware alles meesleur saam met 'n groot magtige stroom: die staatsadministrasie, die onderwys, die hele ekonomiese lewe, die massamedia. Instellings soos die kerk wat nie regstreeks by amptelike erkenning betrokke is nie, word op die duur daardeur bedreig. Dit blyk duidelik uit J. du P. Scholtz se werk Die Afrikaner en sy taal 1806 - 1875 (1965). Hy het aangetoon hoe die feit dat Engels in die 19 de-eeuse Kaapkolonie die enigste ampstaal was, as argument gedien het vir diegene wat ook die kerk wou verengels. Hy gee 'n opsomming van 'n stuk wat in 1856 in De Kerkbode (16 Februarie 1856) gebruik is om krag by te sit by die argumente vir die invoer van Engelse dienste in die Groote Kerk.

Uit die lang betoog van die Kerkbode-skrywer oor hoe Engels veld wen en op alle terreine onontbeerlik word, kan die volgende tersaaklike stukkie aangehaal word:

Omdat die taal van die gocwerment, van die regbank, die wetgewende liggame, van die handel Engels is, sal jongmense geen moeite doen om hul cic taal te leer nie en Engels behoort in die kerk ingevoer te word om te kecr dat die jong mense na die Engelse kerk oorloop (opgesom deur Scholtz, 1965:114$115)$.

Amptelike Engels-eentaligheid sal die eerste 'n invloed uitoefen op die terreine wat direk deur so 'n beleid geraak word soos die onderwys en staatsdiens. Afrikaans sal 'n knou kry as wetenskapstaal, of algemener gestel, as intellektuele taal. 


\subsection{Uitfasering van Afrikaans as onderrigmedium}

'n Staatsbeleid van amptelike Engels-eentaligheid sal meehelp om Afrikaans as voertaal aan universiteite te ondermyn - eers deur die aanvaarding van dubbelmedium, en daarna deur aanvaarding van Engels as enigste doseertaal. Verlies van status gaan bowendien waarskynlik impliseer dat Afrikaans moeilik 'n algemene skoolvak aan nie-Afrikaanse skole sal bly. Aan swart skole is Engels die onderrigmedium. Wie deur middel van Engels gematrikuleer en Afrikaans nie eens as vak gehad het nie, sal ook sy universiteitsopleiding deur medium van Engels wil hê, selfs aan Afrikaanse universiteite.

Die verdwyning van Afrikaans as ampstaal sal direkte gevolge hê vir die onderrig van die vak Afrikaans op sekondêre vlak. By skole onder die Departement Onderwys en Opleiding, waar Afrikaans as vak nie meer verpligtend is nie, is daar reeds 'n tendens om Afrikaans glad nie meer as vak aan te bied nie. Die waarskynlikste scenario vir taalonderwys in die toekoms is een waarvolgens die betrokke onderwysowerheid self besluit watter taal in sy skole as eerste taal aangebied gaan word (feitlik vanselfsprekend die ampstaal). Die keuse van 'n tweede taal gaan egter berus op ander faktore soos wát die betrokke moedertaal van die betrokke leerlinge is. Dit is moeilik denkbaar dat enige onderwysowerheid sonder meer tot Afrikaans as tweede taal sal besluit as dit geen amptelike erkenning geniet nie. Sodoende kan Afrikaans as onderrigtaal buite die Afrikaansmediumskole (wat self gaan kwyn) feitlik verdwyn. Dit hou enorme implikasies in vir die Afrikaanse boek, die Afrikaansonderwyser en die potensiële tweedetaalsprekers van Afrikaans, veral as 'n mens daaraan dink dat die Departement van Onderwys en Opleiding in 1991 bykans 280000 kandidate gehad het wat Afrikaans as vak neem en geregistreer het vir die matrikulasieeksamen daarin.

Meer as net 'boeke' gaan geraak word - eintlik alles wat in Afrikaans gepubliseer word, soos ook studiehandleidings, opleidingsdokumente en dergelike, en sodoende dus sowel die formele as nie-formele sektor van onderrig. Duisende Afrikaanssprekendes sal derhalwe hul (geskrewe) opleiding as eiendomsagente, prokureursklerke en dergelike teen wil en dank in Engels ontvang - so iets het naas ekonomiese gevolge ook gevolge vir die taalregisters - waaroor later meer.

\subsection{Die verskraling van Afrikaans as wetenskapstaal}

Afrikaans word tans ook aan instellings soos die RGN, en in minder belangrike mate die MNR en WNNR, as wetenskapstaal gebruik. Met Engels as enigste ampstaal het Afrikaans by hierdie instansies geen hoop om as wetenskapstaal te oorleef nie.

Die moontlikheid bestaan dat wetenskaplike publikasies onder 'n nuwe taalbeleid kan ly. 'n Hele aantal geakkrediteerde vaktydskrifte word deur 'n staatsinstelling uitgegee, naamlik die Buro vir Wetenskaplike Publikasies. Die Buro sou kon eis dat alle artikels in Engels moet wees, en die Departement van Nasionale Onderwys dat hy net Engelse artikels vir subsidie in aanmerking neem indien die huidige subsidiebeleid voortgesit word.

Dit kan tot gevolg hê dat Afrikaans mettertyd sy diversiteit gaan verloor omdat bepaalde registers in onbruik kan raak. ('Register' word hier in sy sosiolinguistiese betekenis gebruik 
van taalvariëteite wat verbonde is aan bepaalde beroepe, vakgebiede en onderwerpe.) Registers verryk veral op leksikale vlak die taal. Met die agteruitgang van 'n taal as wetenskapstaal kom daar verval in sy verskillende wetenskapsregisters.

Daarby word bepaalde registers direk geraak deur die amptelike status, soos dié van die wetgewende, uitvoerende en regterlike funksies van die staat. Albie Sachs het in een van sy toesprake verklaar dat Afrikaans dalk in die toekoms nie meer die sogenaamde "taal van amptelike rekords" sal wees nie (Anon, 1990:3).

Die prysgee van belangrike gebruiksfunksies en die taalregisters wat daarmee saamhang, is ook 'n verlies vir die letterkunde. Die letterkunde is in taalopsig imperialisties én parasities: hy eien hom nie net die gebruiksfunksies van taal op alle terreine toe nie, hy buit dit uit op allerlei maniere en is in sekere opsig selfs daarvan afhanklik. So byvoorbeeld word wetenskapsregisters in die poësie benut en verfyn. burokratiese taalgebruik en die taal van amptelike rekords' geparodieer en die begrippe van die genetika en fisika en dergelike omvorm tot die grondstof vir wetenskapsfiksie. Sonder hierdie wetenskapsregister is die verhale van byvoorbeeld Pierre Haarhoff en 'n Plaston van P.G. du Plessis skaars denkbaar.

\subsection{Minder Afrikaans in staatsgesubsidieerde toneel}

Verandering in die status van Afrikaans as ampstaal kan en sal geweldige gevolge inhou vir byvoorbeeld die staatsgesubsidieerde toneel en die hele struktuur van die streeksrade in: den brede. In Namibië het Mees Xteen hom in 'n persoonlike gesprek mel een van die skrywers van hierdie stuk verklaar dat hy hom verplig voel om die ampstaal Engels veel meer te laat gebruik in die opvoerings van die nuwe ekwivalent van SWARUK. Dit is die staatsubsidie wat eksperimentering moontlik maak. Daarsonder sou toneelgeselskappe hulle net soos in vervloë tye moet bepaal by bewese lokettreffers.

\subsection{Samewerking met Europese verwante}

Optimiste sien in die toekoms veel nouer skakeling tussen sprekers van Afrikaans aan die een kant en van Nederlands (in Nederland en België) aan die ander. Dit sou volgens hierdie siening die noodwendige gevolg wees van die verdwyning van die albatros van apartheid wat lank om die nek van Afrikaans gehang het. Maar in werklikheid het die groter belangstelling van Nederlandse kant ook te make met die feit dat Afrikaans as ampstaal vir die Nederlande bepaalde voordele inhou. Suid-Afrika vorm 'n klein afsetgebied vir Nederlandse boeke en plate, asook vir televisieprogramme (en laasgenoemde sal daarvan afhang of Afrikaans 'n amptelike en derhalwe televisietaal bly), terwyl die feit dat miljoene mense in 'n ander wêrelddeel 'n standaardtaal praat en skryf wat nou met Nederlands verwant is, krag verleen aan dié taal se aansprake om een van die offisiële tale van die Europese gemeenskap te bly. Hierdie samewerking, glo baie, kan selfs ook amptelike beslag kry soos die insluiting van Afrikaans in die Nederlandse Taalunie. Een van die struikelblokke wat tans bestaan in die samewerking tussen Nederland en België (eintlik Vlaandere) is die feit dat België veel minder geld bewillig vir ondersteuning van die kunste - veral die letterkunde. In Suid-Afrika is die totale bedrag vir staatsondersteuning ten 
opsigte van die letterkunde tans ongeveer R400 000 . Wanneer dit vergelyk word met die R35 miljoen in Nederland en R6 miljoen in Vlaandere blyk dit maar 'n druppel in 'n emmer te wees. Verloor Afrikaans sy amptelike status sou dit beteken dat die huidige aanspraak op sy deel van die druppeltjie boonop sal verdwyn. Samewerking met sy Europese verwante kan so kwaai geknou word.

\subsection{Minder Afrikaans in die massamedia}

Amptelike Engels-eentaligheid kan die uitsaaiwese raak. Die massamedia, veral radio en televisie, word oral beskou as van kardinale belang in die handhawing van minderheidstale. Dis geen wonder nie dat 'n Europese liggaam onlangs heelwat aandag bestee het aan die belang van gereelde radio- en televisie-uitsendings in minderheidstale. ${ }^{3}$

Die radio en televisie help om die standaardtaal te vestig en uit te bou. Daarby is die taal van die massamedia in sekere sin die huistaal - in die minder algemene betekenis van 'taal wat gereeld in die huis gebesig word'. Televisie help op die oomblik dat Afrikaans 'n lewende taal bly. Die massa kry vermaak en inligting in Afrikaans, ook inligting in verband met die Afrikaanse letterkunde. Deur besprekings daarvan en deur die dramatisering van letterkundige werke kry die Afrikaanse letterkunde nuwe lewe. Wat van belang is, is nie net die blootstelling aan Afrikaans wat verlore sal raak nie, maar 'n hele wêreld van vermaak en inligting wat vreemd gaan word aan Afrikaans. ${ }^{4}$ Uiteraard beteken dit ook inkorting van Afrikaanse reklame - seker dié vorm van taalgebruik wat die nouste verwantskap met die poësie onderhou en nie altyd daarvan onderskei kan word nie. Een van die vermaardste Afrikaanse reklameteksskrywers was die digter G.A. Watermeyer.

Dis moeilik om te sê hoe statusverandering die pers sou raak, omdat die persgroepe tans private ondernemings is. Vir die uitbou van Afrikaans as standaardtaal was die koerante en populêre tydskrifte van enorme belang; mens sou selfs kon sê dat die Afrikaanse taalbeweging daarsonder nie sou geslaag het nie. Hulle vestig die geskrewe standaardtaal by die bevolking, vorm die openbare mening, het soms rigting gegee aan die politiek, het publikasiemoontlikhede geskep en die skryf van Afrikaans daadwerklik aangehelp.

Die Afrikaanse dagblad bereik volgens onlangse syfers elke dag 800000 lesers en die Sondagblad Rapport meer as 'n miljoen.' 5 Soveel mense kom dus elke dag ongedwonge met die standaardtaal in aanraking. Die koerant is dikwels ook 'n toegangspoort tot die letterkunde: nie alleen deur resensies en nuus oor skrywers nie, maar ook deur die voorbeeld van goeie taalgebruik wat dit kan stel. N.P. van Wyk Louw het reeds omstreeks 1960 beweer dat van die beste prosa destyds in 'n koerant verskyn het, naamlik Die Burger, in

\footnotetext{
${ }^{3}$ Vergelyk besluit 192 van dic "Standing Conference of Local and Regional Authorities of Europe" oor
} streeks- en minderheidstale.

${ }^{4}$ Erkenning het ook gevolge vir die toewysing van geld - iets wat veral vir die massamedia van groot belang is. So kry in ' $n$ land soos Switserland Duits, Frans en Italiaans ewe veel geld vir televisie, al is die Duitse taalgemeenskap veel groter as die Franse en Italiaanse.

5 Dit beteken nie dat die koerante hierdie sirkulasies het nie, want meer as een mens lecs uiteraard dieselfde koerant. Dic syfers is deur die destydse redakteur van Die Volksblad, mnr. Hennie van Deventer, in 1990 op 'n taalberaad van dic Afrikaanse Taalfonds verstrek. 
prosa "wat suiwer, intelligent en dikwels geestig is. En aan die literêre kant ... moet die Here maar meestal swaar genoeë neem met wat ons vaderlandse en provinsiale prosaïste oor Sy akker laat vloei" (1986:93).

'n Mens kan nie voorsien hoe 'n Engelse bedeling koerante sal tref nie, maar daar is reeds 'n dalende tendens in die sirkulasie van die Suid-Afrikaanse dagblaaie. Dalende leserstalle lei altyd tot 'n vermindering van advertensies; soms moet publikasies hul deure sluit, selfs al het hulle relatief baie lesers.

Engels-eentaligheid sal heel waarskynlik gevolge hê vir die keuse van koerante waarin staatsadvertensies geplaas word. In Namibië is in 1991 net Engelsmedium-koerante gevra om te tender vir die plasing van staatsadvertensies. Die Republikein, een van die belangrikste koerante van die land, het daarop in 'n hoofartikel geskryf:

Sommer skielik word ons - so wil dit lyk - uit dic mark gerangeer, sonder om selfs die geleentheid te laat vir ons (of enige dergelike kocrant) om ons moontlikhede as kommunikasiekanaal tussen adverteerder (in hierdic geval die staat) en die potensiële tenderaar uit te wys. (Anon, 1991:4.)

Dit is die soort praktyk wat eweneens kan voorkom in 'n Engels-eentalige Suid-Afrika.

Vroeër in hierdie stuk is melding gemaak van 'n literatuursisteem. 'n Mens kan jou afvra of dit moontlik is dat 'n sisteem, of een van die dele daarvan, intak kan bly terwyl die ander dele tot niet raak. Sou die Afrikaanse letterkunde kan groei of ongeskonde biv as die ander soorte literatuur verskrompel of selfs verdwyn? Dis hoogs twyfelagtig.

\section{Demografiese gevolge van die verlies van ampstaalstatus}

' $n$ Tweede kategorie moontlike gevolge van die verlies van amptelike status is demografies van aard.

Verloor Afrikaans sy taalregte, sal dit op baie min terreine van die lewe sy bruikbaarheid en ekonomiese waarde behou. In geen taalgemeenskap kan so 'n ingrypende verandering as verlies van belangrike gebruiksfunksies sonder taalverskuiwing gepaard gaan nie. Dit is die proses waardeur 'n taalgemeenskap of individu sy taal prysgee en 'n ander taal as eerste taal aanneem.

Daar verskyn reeds in die massamedia artikels oor veelseggende nuwe tendense, veral die toename van Afrikaanssprekendes wat hul kinders na Engelse skole stuur; naas ander redes daarvoor word onder meer aangevoer voorbereiding vir die 'Nuwe Suid-Afrika'. Wanneer mense begin voel dat hul taal in die toekoms min waarde gaan hê, dat daar geen loopbaangeleenthede daarin gaan wees nie, dan kies hulle 'vir die beswil van die kinders' onderrig in die taal waarmee hulle wel voorberei word vir die latere lewe. Partykeer volg daarop ' $n$ volgende stap: dat die gesin die skooltaal as huistaal aanneem om die kinders goed voor te berei vir die skoolloopbaan. Afhangende natuurlik van die skaal waarop dit plaasvind, kan taalverskuiwing een van die grootste rampe word wat enige taalgemeenskap kan tref.

Een van die direkte gevolge van so 'n proses op die letterkunde is 'n krimpende getal lesers. 'n Ander is die moontlikheid dat skrywers hulle tot groter taalgemeenskappe wend. 
Waarom sal 'n ambisieuse skrywer wat ook 'n ander taal goed ken, skryf in 'n taal wat lyk of dit geen toekoms het nie? Alleen uit taalgetrouheid, en taalgetrouheid is nie 'n blywende eienskap van taalgebruikers nie.

\section{Ekonomiese gevolge van die verlies van ampstaalstatus}

Daar is nog 'n groep moontlike gevolge, gevolge van ekonomiese aard, wat verlies van ampstaalstatus op die letterkunde kan hê.

Dis moontlik om voorbeelde uit baie state te verstrek van hoe 'n onsimpatieke taalbeleid groot groepe mense stoflik benadeel het. Net een voorbeeld uit die geskiedenis van SuidAfrika. Toe die Kaapkolonie in 1832 'n Engelse geregshof gekry het, is baie mense wat net ondervinding van Hollands gehad het, "daardoor tot de bedelstaf gebracht" (Anon, 1912:89).

Indien Suid-Afrika Engels-eentalig word en dit lei byvoorbeeld tot 'n Engels-eentalige radio en televisie. gaan dit beteken dat 'n groot klomp van ons beste kultuurmense sonder werk raak, omdat die aantal werksgeleenthede verminder. 'n Mens kan byvoorbeeld dink aan omroepers. vertalers en akteurs. Dan is daar vertalers en taalversorgers in diens van s:aatsinstansies. onderwysers en dosente van Afrikaans. Daar is byvoorbeeld die talle wit, bruin en swart onderwysers wat besluit het om hulle in Afrikaans te bekwaam om dit as vak aan te bied.

Wie doelbewus die sosiaal-ekonomiese gevolge van so 'n revolusionêre verandering as wysiging van taalstatus ignoreer, begaan een van die bekende groot sondes van die iwintigste eeu: om idees, en soms bedenklike idees, swaarder te laat weeg as mense.

Of die slagoffers geregverdigde straf vir hul sondes gaan ontvang of nıe. dit is kwalik ter sake. Maar n gemeenskap van arm mense. werkloses, mense wat moet rondval om nuwe werk te kry. Is nie in staat om veel geld te bestee aan boeke, koerante. tydskrifte, toneelopvoerings en dergelike nie; ook nie om die soort instellings op te rig of in stand te hou waarin die taal behoue kan bly nie, soos private skole. ${ }^{6}$

Dan moet 'n mens dink aan die ekonomiese gevolge vir die uitgewerye en boekhandels. Hulle sal geldelik ly onder die verlies aan skoolboeke vir tweedetaalsprekers en die verlies van die mark wat die biblioteekdienste verskaf. Dit le voor die hand dat sulke dienste voorkeur sal gee aan boeke in die amptelike taal. Vir die uitgewers van gespesialiseerde

\footnotetext{
${ }^{6}$ Afgesien daarvan sal Afrikaans-departemente aan universiteite swaar getref word. Dan dink ' $n$ mens nic net aan die feit dat dic afname in Afrikaans-onderwysers ' $n$ afname in die aantal Afrikaansstudente beteken en Afrikaans-departementc heclwal van hul personeellede moet verloor nie. Maar wat dit verder inhou, is dat minder lettcrkundiges sal kan spesialiseer, dat minder mense met gesag oor die Afrikaanse letterkunde sou kon praat. Daar sal waarskynlik sterk aandrang wees dat dic Alrikaanse letterkunde deel word van die nuwe vak South African Literaturc. Afrikaanse lctterkunde, gedoseer deur medium van Engels, sal moontlik in so 'n kursus deur dic jare 'n al hoe kleiner komponent word. Maar wat daarvoor kan vergoed, is miskien 'n groter komponent táalgebruikskunde. meer kursusse Afrikaans Spesiaal soos vroeẻr jare se Duits Spes vir mense wat dic laal nic op skool gehad het nie.
} 
vakgebiede kan 'n besluit tot amptelike Engels-eentaligheid rampspoedig wees - soos vir uitgewers van woordeboeke en regsboeke. Die moontlike aanvaarding van Engels as onderrigmedium hou natuurlik in dat skoolhandboeke in Afrikaans onnodig gaan wees en dat hierdie belangrike mark gaan verdwyn.

Uitgewers sal versigtiger raak om boeke uit te gee. Tans gee uitgewers soms debuutbundels uit omdat hulle daarmee kopiereg kry op die enkele gedigte wat moontlik naderhand in bloemlesings gaan verskyn. Maar 'n mens kan daarop reken dat die mark vir bloemlesings sal agteruitgaan. Dit gaan moeiliker word om iets uit te gee - en dit kan skrywers demoraliseer.

Ons kan die situasie bereik waarin net 'veilige' boeke, voorskryfbare boeke, uitgegee word 'n toestand vergelykbaar met dié in die Afrika-tale: boeke is sinoniem met wat op skool gelees word, of waaraan daar 'n bewese behoefte bestaan soos, in Afrikaans, religieuse literatuur, resepteboeke en miskien enkele algemene werke. Verdaasdonk en Segers (1990) se navorsing toon dat die deelnemers aan die boekkultuur geletterde mense is wat derhalwe ook 'n bepaalde inkomste verdien wat hulle in staat stel om boeke te koop.

\section{Samevattend}

Om terug te kom na die verskillende soorte taalstatus waarna verwys is: 'n verandering van juridiese status het beslis gevolge vir die funksionele status van tale, en dit het meestal gevolge vir die demografiese status. En sodra die status van een taal gewysig word, word dié van die mededingende tale ook verander. Ook die taalgemeenskappe van 'n meertalige staat vorm 'n soort Saussuriaanse sisteem waarin alles met alles saamhang!

In 'n amptelik Engels-eentalige Suid-Afrika gaan die Afrikaanse letterkunde nadelig getref word deur 'n waarskynlik krimpende taalgemeenskap, die verswakking van die geldelike posisie van Afrikaanse uitgewerye, die agteruitgang van die massamedia, die wegval van belangrike funksies van Afrikaans, en die agteruitgang van 'n intellektuele lewe in Afrikaans aan byvoorbeeld universiteite en die beroepswèreld.

Hennie Aucamp (1990:8) het in 'n koerantartikel verwys na onder meer die "gul aanbod" van party letterkundiges dat Afrikaans van sy amptelike status moet afstand doen. Hy het geskryf dat die Afrikaner "fluks besig" is om sy kultuur, waarvan die Afrikaanse letterkunde 'n kernkomponent is, "na die uitverkooptafel aan te dra". Hy vra dan:

Wárom? Om kommersięle redes? Uit onverskilligheid? Of in 'n roes van politieke boetedocning? In krisistye is kultuur geen luukse nie, maar dic hongste vorm van selfbehoud. Want kultuur staan vir interne orde, en interne orde is die fondament van alle beskawing. Moet die waarheid altyd te laat besef word?

Na dit alles gesê is, kan 'n skeptikus tog teëwerp: Wat daarvan? Is die letterkunde nie 'n luukse nie, is dit überhaupt nodig in ons derdewêreldsituasie?

Daar kan volstaan word met enkele menings van ander. Die eerste is dié van prof. Alan Warner van die Universiteit van Kampala oor wie se intreelesing Coenie Slabber in Rapport geskryf het (1990:14). Warner het aan studente van Afrika gesê: 
Die groot skrywers skryf oor hullesclf en oor hul eie tyc, maar hulle kan julle help om jul cic sclf en jul eie wêreld beter te verstaan. Hulle sal vir julle 'n dieper bewus-wees bring van dic gloric en die terreur van die menslike bestaan. Deur hulle sal julle meer ten volle die gees erf, nic van die wit man of dic bruin man of die swart man nie, maar dic gees wat geen kleur het nic, die gees van die mensheid.

Die universele aard van letterkunde en die algemene waarhede daarin vervat, maak nie die taalspesifieke aard daarvan ongeldig nie.

Van Wyk Louw (1986:164) skryf:

Is dit nie dic groot literatuur wat dic bestaan van ons volk as aparte taalgroep regverdig nie? Eintlik moet ons hele geestelike lewe ons bestaan regverdig in soverre as die lewe 'n bydrae tot die rykdom van die mensheid is, maar binne daardie geestelike goedere staan die literatuur nog weer alleen in sy betekenis - ons sou ander groot kuns, groot wetenskap en groot godservaring kon gehad het selfs as ons nie meer 'n aparte Afrikaanse vulk was nie; maar ons hele strewe om deur ons taal voort te bestaan, kan geregverdig word alleen deur die rykdom van onvervangbare waardes wat ons in dié taal voortbring.

\section{Bibliografie}

Anon. 1910. Statutes of the Orange River Colony, 1909 / Wetten van de Oranje Rivicr Kolonic, 1909. Blocmfontcin : The Argus Printing and Publishing Co.

Anon. 1912. Hoe onze taal aan haar rechten is gekomen/ Een terugblik op de taalstrijd in het Parlement / Chronologiese schets. De Zuidafrikaan verenigd met Ons Land :8-9, Scpt. 19.

Anon. 1990a. Namibic: Engclse nuus. Beeld :2, Mci 5.

Anon. 1990b. Afrikaans sal gesond bly en corleef - Sachs. Beeld :3, Sept. 4.

Anon. 1991. Honfartikel. Die Republikein :4, Jul. 12.

Aucamp, Hennie 1990. Boeke sonder winkels. Die Burger :8, Jun. 6

Alcock, A.E., Taylor, B.K. \& Welton, J.M. (cds.). 1979. The Future of Cultural Minorities. London Basingstoke : Macmillan

Cobarrubias, Juan 1983. Ethical Issues in Status Planning. In: Juan Cobarrubias \& Joshua Fishman (cds.) Progress in Language Planning. Berlin/New York/Amsterdam : Mouton, pp. 41-86.

Cooper, Robert L. 1989. Language Planning and Social Change. Cambridge : Cambridge University Press.

Fishman, J.A.. 1971. The Sociology of Language: An Interdisciplinary Social Science Approach to Language in Society. In: Fishman, J. (cd.). Advances in the Sociology of Language. Vol. I. Den Haag/Paris : Mouton. pp. 217-404.

Louw, N.P. van Wyk. 1986. Versamelde prosa 2. Kaapstad : Human \& Rousscau.

Scholtz, J. du P. 19652. Die Afrikaner en sy taal 1806-1875. Kaapstad : Nasou.

Schuring, G.K. 1990. Taalbeplanning vir 'n nuwe Suid-Afrika. Pretoria : RGN.

Slabber, Coenie 1990. Nee, 'n nuwe Suid-Afrika het juis sulke 'onpraktiese' oplossings nodig. Rapport :14, Jul. 22.

Unesco. 1968. The Use of Vernacular Languages in Education: The Report of the Unesco Mecting of Specialists. In: Fishman, J.A. (ed.) Readings in the Sociology of Language. Den Haag/Paris/New York: Mouton. pp. 688-716.

Van Rensburg, Christo 1990. Bywoning van kongres oor minderheidstale in Hong-Kong, 12-15 Februaric 1990. LVSA: Byblad 9, 2:19-22

Verdaasdonk, H. \& Seegers, G. 1990. The Impact of Socioeconomic Variables on Cultural Bchavior. Poetics, 19:359-375.

Walters, D.B. 1978. The Legal Recognition and Protection of Language Pluralism. (A Comparative Study with Spccial Reference to Belgium, Quebec and Wales.) Acta Juridica. Essays in Honour of Ben Beinant, Pan III. Kaapstad : Juta. pp. 305-326.

\section{Universiteit van die Oranje-Vrystaat}

